\title{
Dermoscopic description of trichoepithelioma in the skin of colour
}

\section{Subrata Malakar', Samipa Samir Mukherjee ${ }^{2}$}

\author{
${ }^{1}$ Department of Dermatology, Rita Skin Foundation, Kolkata, India, ${ }^{2}$ Department of Dermatology, Cutis Academy of \\ Cutaneous Sciences, Bangalore, India
}

Corresponding author: Dr. Samipa Samir Mukherjee. E-mail: drsamipamukherjee@gmail.com

Sir,

Skin colored flat topped lesions on the face more often than not pose as a diagnostic dilemma to the treating physician. Establishing the diagnosis in such a case depends generally on the clinical presentation history and invasive diagnostic techniques like histopathology, which however is not very popular on the face owing to the risk of scarring. In recent years dermoscopy is gaining appreciation in the diagnosis of various skin diseases where diagnosis is made by better visualization of the surface and sub surface structures, the permutation and combination of which leads to specific diagnosis.

A 28year old lady presented to the outpatient dermatology department with complaints of asymptomatic raised lesions on the face of 15 months duration (Fig. 1). Although asymptomatic they were slowly increasing in size and extent for which no treatment was taken in the past. The lesions were localized over the centrofacial area. History did not reveal any seasonal variation with regards to the size of the lesions. Medical, family and past history was non-contributory in the patient. Clinical examination revealed multiple, discrete $3 \mathrm{~mm}$ to $6 \mathrm{~mm}$ skin colored flat topped to dome shaped papular lesions localized over the area. The differential diagnosis considered at this stage included syringomas, eccrine hydrocystomas, trichoepithellioma and papular sarcoidosis.

Dermoscopic examination of the lesions revealed a whitish background, in focus arborizing vessels, few lesions in addition demonstrated milia like cysts while others showed rosettes (Fig. 2).
Histopathological examination revealed, well circumscribed dermal tumour with branched nests if basaloid cells, small keratin cysts and a dense collagenous stroma with fibroblasts suggestive of trichoepithelioma.

A diagnosis of trichoepithelioma was established on the basis of clinical examination, dermoscopy and histopathological evaluation.

Trichoepitheliomas are not so common benign hamartomatous tumours of the pilosebaceous unit

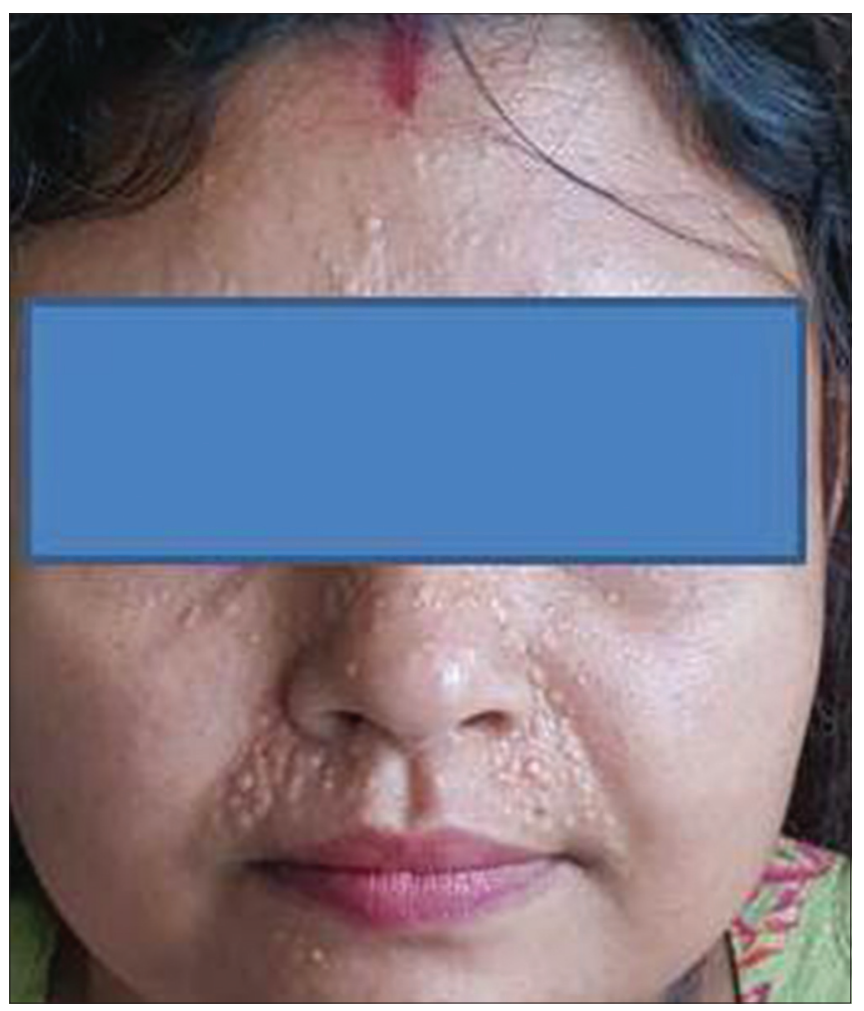

Figure 1: Asymptomatic skin colored flat topped papular lesions on the face in a centrofacial distribution.

\footnotetext{
How to cite this article: Malakar S, Mukherjee SS. Dermoscopic description of trichoepithelioma in the skin of colour. Our Dermatol Online. 2018;9(3):335-336 Submission: 17.10.2017; Acceptance: 08.04.2018

DOI: 10.7241/ourd.20183.29
} 


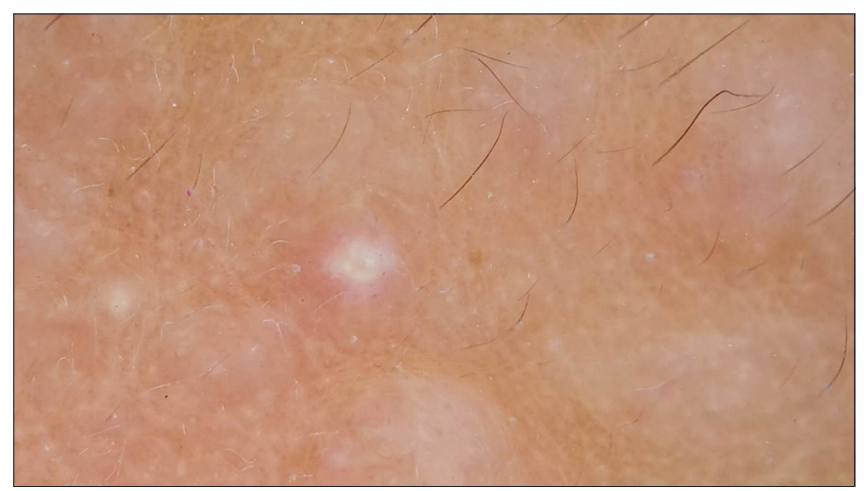

Figure 2: Dermoscopy showing a whitish background, in focus arborizing vessels, few lesions in addition demonstrated milia like cysts while others showed rosettes

which when present cause minor cosmetic concern to the patient. Multiple familial trichoepithelioma constitute an autosomal dominant disease characterized by the appearance of multiple flesh-colored, symmetrical papules, tumors and/or nodules located in the central face and occasionally on the scalp [1]. They may cause functional impairment when present on vital areas like periocular. Although most of the times clinical examination may clinch the diagnosis to a trained eye, it may more often than not pose a diagnostic challenge to many. Dermoscopy forms a non invasive diagnostic technique, the findings of which when interpreted correctly improves the accuracy of diagnosis. While evaluating a papular lesion the parameters evaluated include the back ground colour, vascular pattern, presence of pigmentary network, white shiny structures in the form of milia like cysts or rosettes. Although a facial papule displaying arborizing vessels and shiny white structures under dermoscopy is highly suggestive of basal cell carcinoma, the patient's clinical history and the presence of numerous identical lesions raised the clinician's suspicion for multiple familial trichoepithelioma [2]. Dermoscopy in our patient revealed arborizing vessels, milia like cysts. However most of the lesions in our patient demonstrated the presence of rosettes.

Vascular pattern depicting arborizing vessels or linear vessels suggest the lifting up of overlying skin with vascular proliferation. The background colour whether erythematous or whitish will depend on proliferation of fibroblasts and presence of collagenous material or an underlying inflammatory pathology. The milia like cysts on dermoscopy correspond to the keratinous cysts on histopathology [3]. Rosettes are peculiar structures only observed with polarized dermoscopy and are defined as four white points, arranged as a four leaf clover [4]. Another view suggests that they arise from Interaction of the polarized light with narrowed or keratin filled adnexal openings [5]. Others suggested that rosettes correspond to an alternating focal hyperkeratosis and normal corneal layer and keratin filled openings [6]. Haspeslagh et al in their study stated that rosettes are an optical effect of crossed polarization by concentric fibrosis or horny material and hence are not lesion-specific [7]. Also these structures are more commonly seen in actinic skin. This probably explains the demonstration of rosettes in our case of trichoepithelioma where concentric fibrosis was seen on histopathology and also the lesions being located in the actinic area of face.

To the best of our knowledge there is no documentation of rosettes in trichoepithelioma in the skin of color. However continuous observations require to be made and documented in order to suggest rosettes as a consistent finding in trichoepitheliomas in the skin of colour.

\section{CONSENT}

The examination of the patient was conducted according to the Declaration of Helsinki principles.

\section{REFERENCES}

1. Mapar MA, Ranjbari N, Afshar N, Karimzadeh I, Karimzadeh A Indian J Dermatol Venereol Leprol. 2014;80:349-52.

2. Navarrete-Dechent C, Bajaj S, Marghoob AA, González S, Muñoz D. Multiple familial trichoepithelioma: confirmation via dermoscopy. Dermatol Pract Concept. 2016;6:51-4.

3. Stricklin SM, Stoecker WV, Oliviero MC, Rabinovitz HS, Mahajan SK. Cloudy and starry milia-like cysts: how well do they distinguish seborrheic keratoses from malignant melanomas? J Eur Acad Dermatol Venereol. 2011;25:1222-4.

4. Cuellar F, Vilalta A, Puig S, Palou J, Salerni G, Malvehy J. New dermoscopic pattern in actinic keratosis and related conditions. Arch Dermatol. 2009;145:732.

5. Liebman TN, Rabinovitz HS, Balagula Y, Jaimes-Lopez N, Marghoob AA. White shiny structures: dermoscopic features revealed under polarized light. J Eur Acad Dermatol Venereol. 2012;26:1493-7.

6. Liebman TN, Rabinovitz HS, Balagula Y, Jaimes-Lopez N, Marghoob AA. White shiny structures: dermoscopic features revealed under polarized light. J Eur Acad Dermatol Venereol. 2012;26:1493-7.

7. Haspeslagh M, Noë M, De Wispelaere I, Degryse N, Vossaert K, Lanssens S, et al. Rosettes and other white shiny structures in polarized dermoscopy: histological correlate and optical explanation. J Eur Acad Dermatol Venereol. 2016;30:311-3.

Copyright by Subrata Malakar, et al. This is an open-access article distributed under the terms of the Creative Commons Attribution License, which permits unrestricted use, distribution, and reproduction in any medium, provided the original author and source are credited.

Source of Support: Nil, Conflict of Interest: None declared. 